\title{
Erratum to: Converting to a Common Data Model: What is Lost in Translation?
}

\author{
Peter R. Rijnbeek
}

Published online: 7 October 2014

(c) Springer International Publishing Switzerland 2014

\section{Erratum to: Drug Saf}

DOI 10.1007/s40264-014-0221-4

An error was subsequently identified in the article, and the following correction should be noted:

\section{Acknowledgements}

The following sentences, which previously read:

"No sources of funding were used to assist in the preparation of this commentary. Peter R. Rijnbeek works in a group that has received funding from European Commission and several pharmaceutical companies. Dr Rijnbeek has no other conflicts of interest that are directly related to the content of this commentary."

Should read:

"No sources of funding were used to assist in the preparation of this commentary. Peter R. Rijnbeek works in a group that has received funding from European Commission and several pharmaceutical companies. The Department of Medical Informatics has in the past received funding from OMOP. Dr Rijnbeek has no other conflicts of interest that are directly related to the content of this commentary."

The online version of the original article can be found under doi:10.1007/s40264-014-0221-4.

P. R. Rijnbeek ( $₫)$

Department of Medical Informatics, Erasmus Medical Center,

Rotterdam, The Netherlands

e-mail: p.rijnbeek@erasmusmc.nl 